\title{
Design optimisation of a wireless sensor node using a temperature-based test plan
}

\author{
Lorenzo Ciani ${ }^{1}$, Marcantonio Catelani ${ }^{1}$, Alessandro Bartolini ${ }^{1}$, Giulia Guidi ${ }^{1}$, Gabriele Patrizi ${ }^{1}$ \\ ${ }^{1}$ Department of Information Engineering, University of Florence, via di Santa Marta 3, 50139, Florence, Italy
}

\section{ABSTRACT}

The introduction of Big Data and Internet of Things has allowed the rapid development of smart farming technologies. Usually, systems implemented in smart farms monitor environmental conditions and soil parameter to improve productivity, to optimize soil conservation, to save water and to limit plant diseases. Wireless sensor networks are a widespread solution because they allow to implement effective and efficient crop monitoring. At the same time, wireless sensor networks can cover large area, they can ensure fault tolerance and they can acquire large amount of data. Recent literature misses to consider the testing of the hardware performances of such systems according to the actual operating conditions. The effects of a harsh environment on the dynamic metrological performances of sensor nodes are not sufficiently investigated. Consequently, this work deals with the electrical design optimization of a sensor node by means of thermal test used to reproduce the actual operating conditions of the nodes. The results of the node characterization through thermal tests are used to improve the node's design and consequently to achieve higher performances in harsh operative conditions.

\section{Section: RESEARCH PAPER}

Keywords: Fault Diagnosis; Precision farming; Temperature; Testing; Wireless Sensor Network

Citation: Lorenzo Ciani, Marcantonio Catelani, Alessandro Bartolini, Giulia Guidi, Gabriele Patrizi, Design optimisation of a wireless sensor node using a temperature-based test plan, Acta IMEKO, vol. 10, no. 2, article 7, June 2021, identifier: IMEKO-ACTA-10 (2021)-02-07

Section Editor: Giuseppe Caravello, Università degli Studi di Palermo, Italy

Received January 14, 2021; In final form June 7, 2021; Published June 2021

Copyright: This is an open-access article distributed under the terms of the Creative Commons Attribution 3.0 License, which permits unrestricted use, distribution, and reproduction in any medium, provided the original author and source are credited.

Corresponding author: Gabriele Patrizi, e-mail: gabriele.patrizi@unifi.it

\section{INTRODUCTION}

Nowadays, automatic measurement systems and Condition Monitoring (CM) tools have become valid and reliable means extensively used in several Internet of Things (IoT) applications in different fields of the Industry 4.0 scenario [1]-[10]. The continuous monitoring of both environmental conditions and soil parameters has become extremely important in agriculture applications [11]. According to [12] the environmental factors such as temperature and humidity have a deep influence on plant pathogens such as bacteria, fungi, and viruses. Moreover, the continuous monitoring of the soil parameters allows to automatise irrigation and consequently minimise the water waste [13]-[15]. Lezoche et al. [16] explained in detail the several advantages achieved integrating internet of things (IoT) technologies inside the agricultural industry, such as productivity improvements, soil conservation, water saving and minimisation of plant diseases. Usually, a Wireless Sensor Network (WSN) is designed and implemented to monitor the crop. The network has to endure harsh outdoor conditions, facing both hot summers and cold winters. At the same time the network has to guarantee service continuity ensuring accurate and reliable data. According to [17] an optimal sensor node for agricultural applications should composed by the following units: a power unit, a processing unit, a memory unit, a sensing unit, and a communication unit. In particular, the thorough analysis presented in [17] highlights the importance of using soil moisture, relative humidity, temperature, and gas sensors.

Recent literature has plenty of papers focusing on the design of innovative wireless network for agricultural purposes. Each of the papers deals with the optimisation of one particular aspect of the network. The nodes deployment is one of the most critical design aspect since it severely affects connectivity, coverage area and reliability of the entire network [18]-[20]. Some papers such as [21], [22] introduce new routing strategies to solve classical drawbacks of WSNs and optimise the transmission based on the actual nodes deployment. Another fully discussed problem regards the optimisation of power consumption which is solved with many different solutions [23]-[25]. For instance, in [26], the authors propose a thermal modeling and characterisation for designing reliable power converters, while [27] focuses on risk 
analysis of photovoltaic panels. In [28], a wireless charging method for the batteries management in agriculture applications is presented. Other papers choose to optimise the design based on the type of plantation. For instance, the design of a low-power sensor node for rice field based on hybrid antenna is presented in [29]. Jiaxing et al. [30] improves the design of sensor nodes in litchi plantation dealing with the coverage area of each node and the micro-irrigation management efficiency. In [31] a low-cost weather station for edamame farm is presented and compared with commercial systems.

As presented above, many recent works deal with design and development of WSN for precision farming. Quite the opposite, the concept of testing the hardware performances according to the actual operating conditions is not adequately addressed. The effects of the operating environment on the dynamic metrological performances of WSN are not sufficiently investigated. As observed in previous works on similar systems [32]-[36], environmental stresses such as temperature, humidity, vibration and mechanical shocks deeply influence both reliability and metrological performances of low-cost electronic components, leading to loss of calibrations, measurement variability and a significant growth in component failure rate.

Trying to fill these needs, this paper deals with the electrical design optimisation of a sensor node using thermal test. The agriculture field of applications is taken into account in order to customise the test plan and characterise the node under its actual operating conditions. The results of the node characterisation through thermal tests are used to improve the node's design and consequently to achieve higher performances in harsh operative conditions.

Unfortunately, there are no international standards regarding environmental tests of WSN, as well as customised standard concerning electronic component testing for agricultural applications are not available. For these reasons, this paper proposes a customised test plan and test-bed for the performances characterisation of a sensor node under temperature stress.

The paper is organised as follows: Section 2 illustrates the initial design of the sensor node developed in this work. Section 3 explain the proposed temperature-based test plan composed by three different test procedures (namely T.1. - T.2. - T.3.). Section 4 summarises the main results of the tests and it proposes some design improvements to optimise the performances of the node. Finally, in Section 5 conclusions are drawn.

\section{SENSOR NODE DEVELOPED IN THIS WORK}

Typically, the classical WSNs are implemented using a single central node (Access Point - AP) directly connected to all the other nodes (which are called peripheral) in the network. The peripheral nodes use a set of several sensors to acquire a large amount of data, then they send the data to the AP which must collect and store them [25], [37]. The main drawbacks are the limited coverage area and the restricted number of nodes. An advanced WSN architecture is the one based on mesh topology, generally called Wireless Mesh Network (WMN). A WMN is an optimal solution when it is required to monitor large geographical areas. More in detail, a WMN is a self-organised and self-configured system made up by lots of peripheral nodes and a single central node (called root node in the following) that manages the whole network. Every node is able to interact with the nearby nodes, using them to reach the root node trough indirect paths, allowing large-area coverage [38]-[40]. Furthermore, WMNs use several near nodes and dynamic routing tables to achieve high-frequency transmissions, high bitrate, full scalability and low management cost [41]-[43].

Figure 1 shows the block diagram of the developed sensor node. It is composed by the following units:

- A power supply unit composed by a photovoltaic panel, two lithium batteries, a "Batteries Management System" (BMS) and a "Maximum Power Point Tracking" (MPPT).

- A set of sensors, including an air temperature and humidity sensor, a soil temperature transducer, a soil moisture sensor and a solar radiation sensor.

- An external antenna.

- A radio and processing unit which is the real core of the sensor node and it is based on the ESP32 system-on-achip microcontroller by "Espressif". The microcontroller is mounted on an evaluation board used for software programming by means of a USB-toUART bridge controllers. The evaluation board also includes pin interface and power supply by means of an AMS1117 LDO. Two 8-channel 12-bit SAR ADCs and two 8-bit DACs are embedded in the ESP32. A customised interface board is used to connect the power unit and the sensors unit to the ESP32 microcontroller.

The network works taking into account two alternative operating phases: a 10 minutes "sleep phase" in which almost all node functionalities are disabled to save energy; and an "active phase" in which the sensors acquire data, the microcontroller elaborates and transmit them to the root node. This type of functioning minimises the duty cycle of the network, allowing a reasonable overheating of the hardware and saving batteries power.

Figure 2 shows two images of the developed sensor node. A detail of the system is illustrated on the left side, while the right image shows the installation on the field.

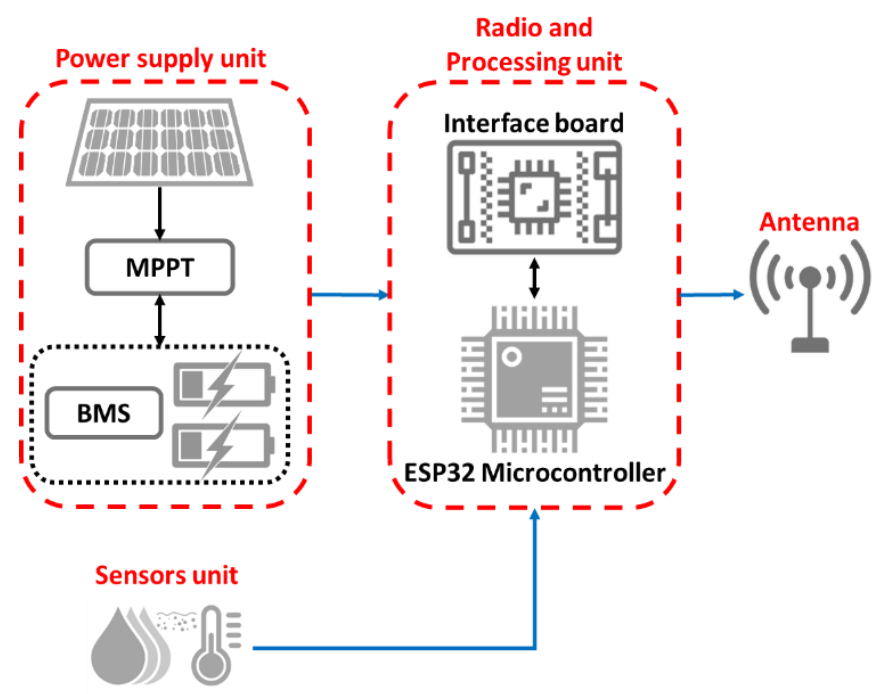

Figure 1. Block diagram of the designed sensor node, including power management systems, radio and processing unit, sensors unit and an external antenna. 

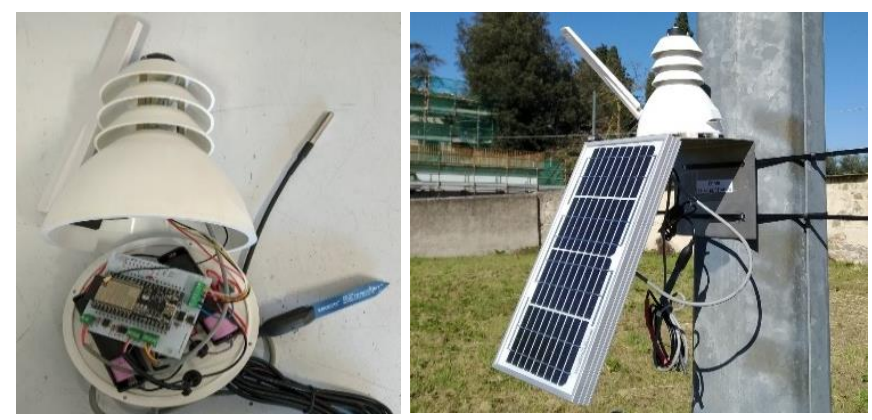

Figure 2. Pictures of the sensor node designed in this work. The left figure shows a detail of the boards enclosed inside a waterproof case, while on the right side the complete system installed on the field is illustrated.

\section{TEMPERATURE-BASED TEST PLAN}

A temperature-based test plan was developed in this work to optimise the design of a sensor node for smart farm applications. Temperature is the optimal stress condition to characterise the hardware of the sensor node and to investigate the weaknesses of the system. In fact, in compliance with the physics of failure of electronic devices, the main failure mechanisms of this kind of systems are intrinsically related to temperature [44], [45]. Temperature is the key acceleration factor for many failure mechanisms such as open/short circuit, silicon fracture, Electrostatic Discharge (ESD), dielectric charging and many others. All these failures could be easily triggered when the temperature reaches high values. Consequently, temperature is the optimal stress since it allows to characterise both operational performances and reliability at the same time. Information acquired during the electrical characterisation under temperature stress are extremely useful to improve the design of the system.

A customised automatic measurement set-up was developed for the acquisition of the key parameter during the temperature tests (see Figure 3). A climatic chamber was used to generate the thermal conditions described above. A datalogger equipped with ten k-type thermocouples was employed to monitor the temperature in some critical points of the developed system. The other equipment illustrated in Figure 3 and used during the tests are a power supply generator, an oscilloscope, a set of multimeters, a current generator and a waveform generator. Furthermore, a root node and a laptop were used to manage the network functionalities and acquire the data.

International standards expressly related to smart agriculture systems are not available. Consequently, several standards that cover similar area were used as guidelines during the design of the test plan, as follow:

- $\quad$ MIL-STD 810G (2008) [46] is a guideline for any kind of environmental stress tests

- IEC 60068-2-14 (2011) [47] provides general procedures for temperature testing

- IEC 60068-5-2 (1990) [48] is a guide to drafting of test methods

- IEC 60068-2-2 (2007) [49] regarding the dry heat test conditions

- IEC 60068-2-38 (2009) [50] provides detailed procedures for temperature cyclic test

- JEDEC JESD22 A104E (2014) [51] covers the temperature test of semiconductor devices

- IEST-RP-PR-003.1 (2012) [52] defines a temperature step-stress profile for accelerating life test.

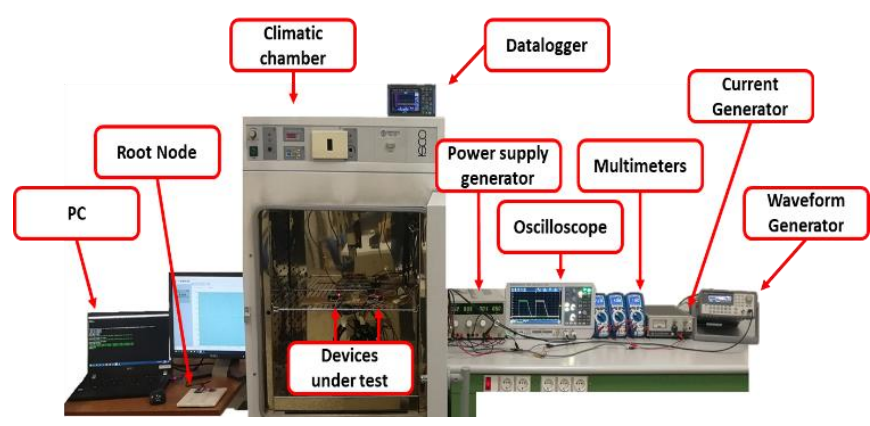

Figure 3. Measurement setup proposed in this work to characterise the designed sensor node under temperature stress.

The developed test plan is based on the aforementioned standards, and it is tailored on the practical application scenario. In particular, the nodes will be deployed in open field, and they will be exposed to harsh environmental conditions. Consequently, the test plan was developed considering the real operating conditions of the node, which must endure extremely high temperature during summer days, and extremely low temperature during winter days. Moreover, the test plan must take into account also the range of guaranteed operability of the component that make the system, as follows:

- Microcontroller and electronic boards (up to $85^{\circ} \mathrm{C}$ ).

- Batteries (from $-10^{\circ} \mathrm{C}$ to $50^{\circ} \mathrm{C}$ ).

Three temperature-based test procedures were developed, namely a positive temperature step-test from $20^{\circ} \mathrm{C}$ to $80^{\circ} \mathrm{C}$ (Test T.1), a back and forth temperature step-test from $-10{ }^{\circ} \mathrm{C}$ to $80{ }^{\circ} \mathrm{C}$ and then again to $-10{ }^{\circ} \mathrm{C}$ (Test T.2) and a temperature cyclic test with restricted temperature range only for battery testing (Test T.3).

\subsection{Test T.1. positive temperature step-test}

In this test procedure the devices under test are two identical sensor nodes. The only different between the two boards is the LDO that manage the power supply of the electronic board. The aim of this test was to characterise the main electrical parameters of the nodes. Only the electronic hardware was tested, the batteries and the solar panel were not located inside the climatic chamber. The first node was supplied by the LDO provided by the manufacturer of the evaluation board (AMS1117 LDO "Former LDO" in the following) and the other one was equipped with a AP2114H LDO ("New LDO" in the following).

The complete temperature profile T.1. is illustrated in Figure 4 , where the blue arrows highlight the temperature step and the exposition time. The test procedure T.1. starts at $20{ }^{\circ} \mathrm{C}$ which is generally the room temperature. The first step consists in a $5{ }^{\circ} \mathrm{C}$ raising temperature lasts 10 minutes.

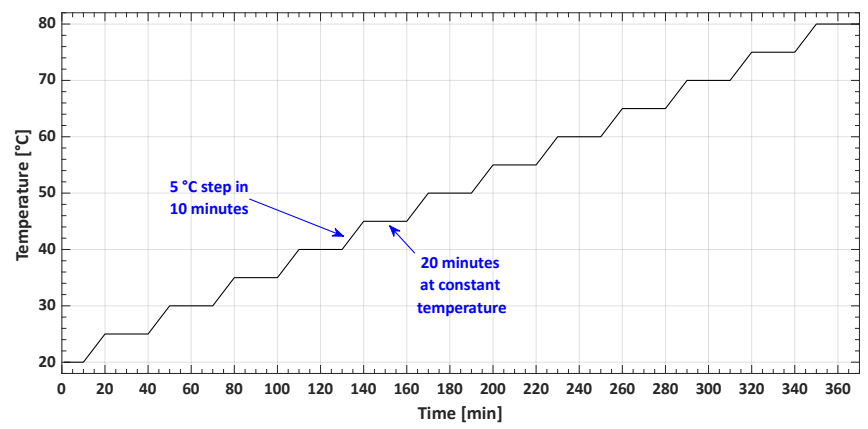

Figure 4. Test procedure T.1. Positive temperature step-test from $20^{\circ} \mathrm{C}$ up to $80^{\circ} \mathrm{C}$. 


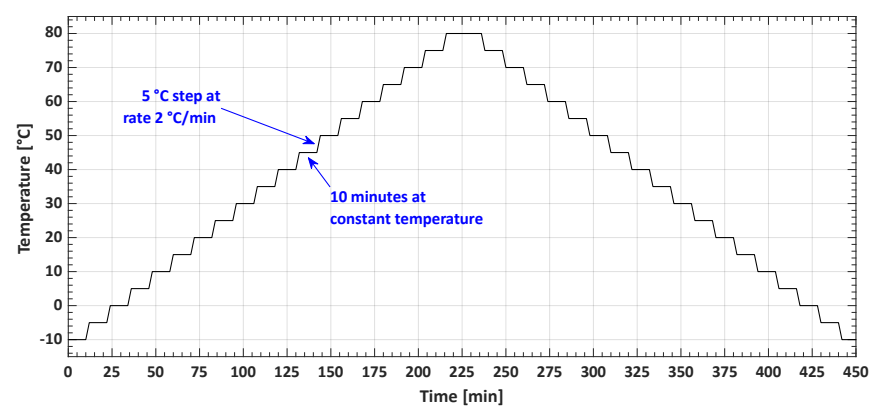

Figure 5. Test procedure T.2. Back and forth temperature step-test from $-10^{\circ} \mathrm{C}$ up to $80^{\circ} \mathrm{C}$ and then back again to $-10^{\circ} \mathrm{C}$.

The rise speed is intentionally kept low to allow components temperature to increase together with chamber temperature.

Then 20 minutes of exposition time at the reached temperature are required to ensure at least two active phases after temperature stability. The two previous steps are repeated up to $80{ }^{\circ} \mathrm{C}$, alternating a $5{ }^{\circ} \mathrm{C}$ step (10 minutes) and a 20 minute exposition time.

\subsection{Test T.2. back and forth temperature step-test}

The test procedure T.2. illustrated in this section is an extension of the test procedure T.1. The differences between the back and forth temperature step-test T.2. and the previous-described procedure are illustrated in the following:

- Temperature range of the test procedure T.2. is from $-10^{\circ} \mathrm{C}$ to $80^{\circ} \mathrm{C}$.

- The test procedure T.2. is repeated back and forth, which means that it starts at $-10{ }^{\circ} \mathrm{C}$, then it reaches $80^{\circ} \mathrm{C}$ following a step increase, and finally it decreases again to $-10^{\circ} \mathrm{C}$ following the same steps.

- Test procedure T.2. is characterised by a rise rate and a lowering rate between one step and the following equal to $2{ }^{\circ} \mathrm{C} / \mathrm{min}$.

- The exposition time at constant temperature of test procedure T.2. is reduced to only 10 minutes.

The complete test profile of the procedure T.2. is illustrated in Figure 5, highlighting the back and forth trend used to investigate hysteresis behaviour.

During this test procedure, only the processing unit of the node was located inside the climatic chamber. In fact, the main purposes of this procedure were to test the performances of the Analog-to-Digital Converter (ADC) and Digital-to-Analog Converter (DAC) embedded in the microcontroller ESP32.

\subsection{Test T.3. Temperature Cyclic Test}

Many papers in recent literature agree that temperature is the key factor in battery degradation [53]-[56]. For this reason, the test procedure T.3. was developed only for battery characterisation. Test procedure T.3 is based on two consecutive cycle. The minimum temperature is $-10{ }^{\circ} \mathrm{C}$, while the maximum temperature is $50^{\circ} \mathrm{C}$. This limited range was designed to satisfy battery safety requirements; nonetheless, it is well representative of the actual operative temperature in agriculture field. The rise rate and the lowering rate is $2{ }^{\circ} \mathrm{C} / \mathrm{min}$, and the exposition time at the minimum and maximum temperature is 30 minutes. Test procedure T.3. is the only procedure in the proposed test plan in which the temperature changes linearly between the minimum and maximum values of the range (without steps).

Figure 6 shows the temperature profile of test T.3. highlighting two cyclic repetitions in the range $\left[-10^{\circ} \mathrm{C} ; 50^{\circ} \mathrm{C}\right]$.

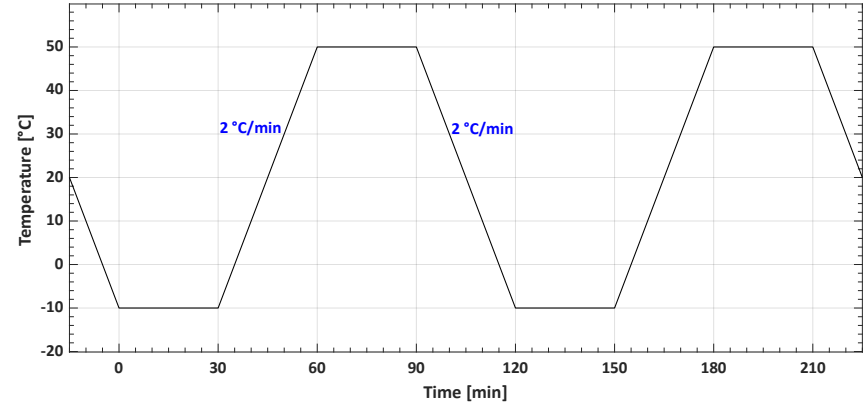

Figure 6. Test procedure T.3. Temperature cyclic test characterised by two tests repetitions.

\section{RESULTS AND DISCUSSION}

In this section the main results achieved during the test are illustrated. Moreover, some design improvements are proposed in order to optimise the performances of the node under the actual operating conditions.

\subsection{Test T.1. main results and proposed improvements}

The node was tested with two different LDOs: the one provided by the manufacturer and a new one. The aim of this procedure is to investigate if the new LDO provides significant upgrades with respect to the former LDO and to evaluate the effect of the temperature, during the step-stress test. Preliminary results regarding this test have been illustrated in [57]. Figure 7 shows the comparison of the current consumption of the two boards (blue and green lines) during six cycles of active and sleep phases, with a corresponding chamber temperature from $55^{\circ} \mathrm{C}$ to $65{ }^{\circ} \mathrm{C}$ (red line). Moreover, Figure 7 highlights the benefits introduced by the new LDO in both active and sleep phases. In fact, the new LDO allows an average decrease of the absorbed current of $2 \mathrm{~mA}$. Figure7 shows the most striking results discovered during the test phase, which is the presence of a current step-up (discovered in both the sensor nodes) at a certain temperature. In case of the former LDO, the step-up occurs approximately around $63{ }^{\circ} \mathrm{C}$, while the new LDO is subjected to this phenomenon at lower temperature (approximately $58^{\circ} \mathrm{C}$ ). Indeed, focusing only on the sleep phase, as shown in Figure 8, it is possible to identify an unexpected increase of about $4.5 \mathrm{~mA}$ of the current above a specific temperature in both nodes. During the cooling phase of the chamber the current consumption suddenly decreases assuming the previous value. After a deep analysis widely explained in [57], this anomaly is due to an unexpected activation of the USB-to-UART bridge controllers (CP2102N) integrated in the evaluation board.

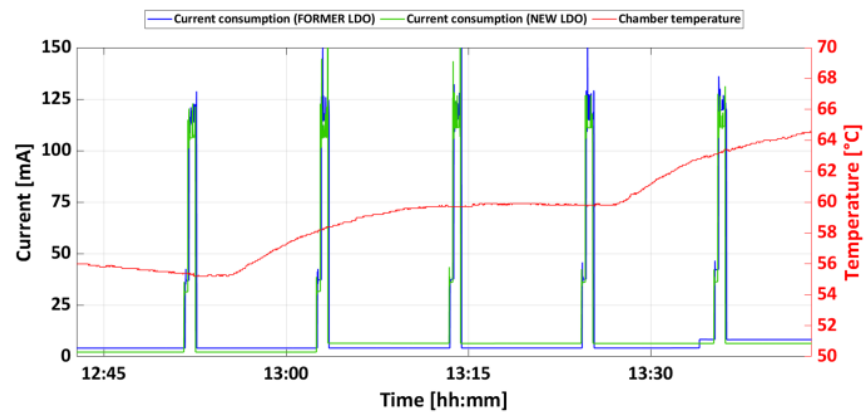

Figure 7. Current consumption of the two boards (blue and green lines) on the left $y$-axis while the right $y$-axis shows the temperature variation of the chamber (red line). 


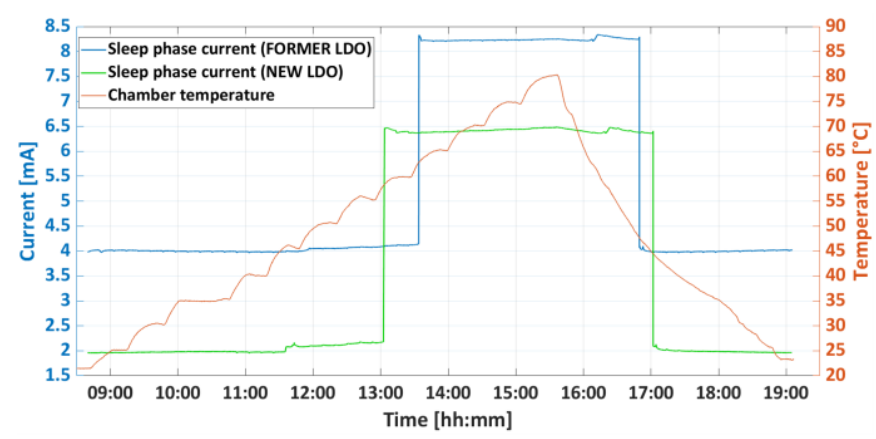

Figure 8. Detail of the current consumption during the sleep phases of the two boards (blue and green lines) on the left $y$-axis while the right $y$-axis shows the temperature variation of the chamber during the test (red line).

The controller should only be activated (or enabled) in case of a device connection to the USB port. The $3.3 \mathrm{~V}$ output of the LDO supplies both USB-to-UART controller and microcontroller. The CP2102N controller is enabled only in case a USB device is connected to the board ( $\left.V_{\text {USB }}\right)$. Under typical operating conditions, the USB provides a $5 \mathrm{~V}$ voltage, then a divider generates a voltage drop ( $\left.V_{\text {BUS }}\right)$ as input of the $8^{\text {th }}$ pin of the USB-to-UART controller. $V_{\text {BUS }}$ is:

$V_{\mathrm{BUS}}=3.41 \mathrm{~V}$.

The CP2102N datasheet highlights that $V_{\mathrm{BUS}}$ pin is considered in a high logical state (controller on) when the following relationships are satisfied:

$$
\begin{aligned}
& V_{\text {BUS }}>(V D D-0.6 \mathrm{~V}) \\
& V_{\text {BUS }}<(V D D+2.5 \mathrm{~V})
\end{aligned}
$$

With $V D D=3.3 \mathrm{~V}$ the high-state threshold can be calculated as:

$$
V_{\text {th }}=V D D-0.6 \mathrm{~V}=3.3 \mathrm{~V}-0.6 \mathrm{~V}=2.7 \mathrm{~V} \text {. }
$$

The board is also powered by an external voltage of $5 \mathrm{~V}$. The controller is disabled by a Schottky diode (BAT760-7) located between the USB connector and the external $5 \mathrm{~V}$ pin. This diode allows to avoid turning on the USB-to-UART bridge with an external 5V supply. Furthermore, it also protects computer or other devices connected via USB from unexpected reverse current. Analysing the Schottky diode datasheet, it is evident that the increase of temperature produces an increase of the reverse current of the diode. For example, at $75{ }^{\circ} \mathrm{C}$ with a $5 \mathrm{~V}$ of reverse voltage the diode exhibits a reverse current of about $100 \mu \mathrm{A}$.

Since the USB connector is an open circuit, the reverse current of the Schottky diode generates a voltage drop given by:

$$
V_{\mathrm{BUS}}=4.75 \mathrm{~V} \gg V_{\mathrm{th}}
$$

Therefore, this reverse current evaluated at $75^{\circ} \mathrm{C}$ is enough to enable the USB-to-UART controller. Furthermore, this reverse current could be dangerous for higher temperatures because it could generate activation voltages higher than the maximum limit, leading to possible damages of the converter. Consequently, the higher the temperature, the higher the diode reverse current, the higher the activation voltage of the CP2102N controller. If the temperature is higher enough to produce a reverse current which generates a $V_{\mathrm{BUS}}>V_{\mathrm{th}}$, then the USB-toUART controller turns on absorbing $4.5 \mathrm{~mA}$ and generating the current step shown in the previous figures.
There are two possible corrective actions to delete this problem guaranteeing the proper functionalities in case of a connected USB device:

- Change the Schottky diode with another model able to guarantee a lower reverse current.

- Modify the divider, for example by maintaining the ratio between the resistances but decreasing the resistance value.

- Design a new Interface Board removing the USB interface and introducing an external serial interface used only during the programming.

The previous considerations explain also the reason why the current step-ups occurred at different temperature in the boards. Indeed, by measuring the outputs of the two LDOs, it is possible to verify a slight difference in the output voltage that leads to a different voltage threshold (4) and, consequently, a different reverse current to activate the USB-to-UART controller.

\subsection{Test T.2. Main Results and proposed improvements}

This test procedure was used to characterise the performances of the internal ADC embedded within the ESP32 microcontroller (simply referred as Internal ADC in the following). To this purpose, a reference signal $V_{\text {in }}=1.5 \mathrm{~V}$ was provided, using a signal generator, as input of the Internal ADC. Moreover, the same signal was also used as input of an additional Analog-toDigital Converter (ADS1115 by Texas Instrument) called External ADC in the following. The External ADC was located on the interface board. It must convert the same signal acquired by the Internal ADC, then the External ADC transfers the digital data to the microcontroller, that store the data into a E2PROM memory. The ADCs acquire 512 samples every two minutes by order of the ESP32 microcontroller. In this way, it is possible to acquire a large amount of data at every considered temperature step. Then, mean value and standard deviation of these samples are calculated to compare the performances of the ADCs.

Figure 9 shows a comparison between the mean value of the 512 acquisitions during each active phase of the two ADCs. The blue-circle markers stand for the mean value of the Internal ADC acquisitions, while the star-blue markers represent the mean value of the External ADC acquisitions. The right y-axis (red axis) is used to depict the temperature of the climatic chamber acquired using a k-type thermocouple and a datalogger during the test.

In the initial phase of the test (room temperature), both ADCs show an offset level with respect the true input value provided by the signal generator. More in detail, the Internal ADC is characterised by a positive offset of $+40 \mathrm{mV}$ which suddenly

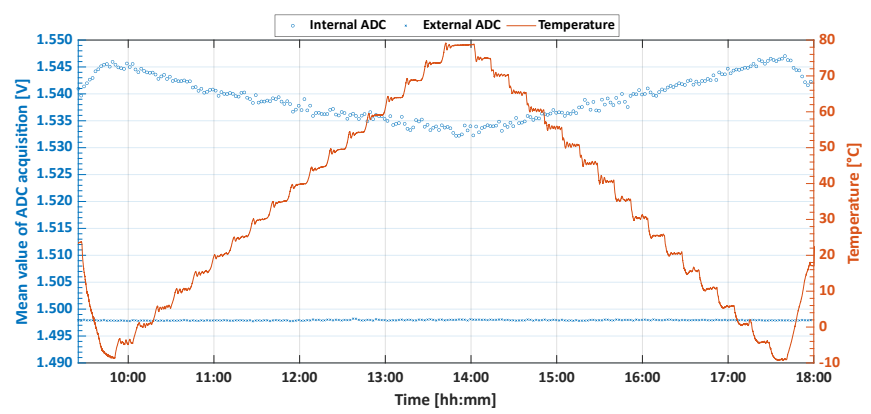

Figure 9. Comparison of the performances of the Internal (blue circle marker) and External (blue star marker) ADCs at each temperature step (red line). Each marker represents the mean value of the 512 acquisition at the considered active phase. 
Table 1. Comparison of the standard deviations for internal and external $\mathrm{ADCs}$ at each temperature.

\begin{tabular}{ccc}
\hline \multirow{2}{*}{ Temperature } & \multicolumn{2}{c}{ Standard Deviation } \\
\cline { 2 - 3 } & Internal ADC & External ADC \\
\hline$-10^{\circ} \mathrm{C}$ & $4 \mathrm{mV}$ & $0.5 \mathrm{mV}$ \\
$10^{\circ} \mathrm{C}$ & $4 \mathrm{mV}$ & $0.6 \mathrm{mV}$ \\
$30{ }^{\circ} \mathrm{C}$ & $8 \mathrm{mV}$ & $0.8 \mathrm{mV}$ \\
$50^{\circ} \mathrm{C}$ & $11 \mathrm{mV}$ & $1 \mathrm{mV}$ \\
\hline
\end{tabular}

increase when temperature is lowered. Quite the opposite, the External ADC has a negative offset of $-2 \mathrm{mV}$. Temperature has a strong influence on the mean value acquired by the Internal ADC (proven by a non-constant trend of the circle markers illustrated in Figure 9). On the other hand, the External ADC highlights a remarkable temperature stability with a semiconstant trend throughout the temperature range.

Table 1 compares the standard deviations of the ADCs under test at some significant temperatures.

The standard deviation of the Internal ADC is quite high and considerably influenced by the temperature of the chamber, while the External ADC highlight better performances in terms of data dispersion.

The introduction of the ADS1115 Analog-to-Digital converter provides better performances in terms of offset at room temperature, thermal stability and data dispersion. For these reasons, it is recommended to integrate this chip instead of the internal ADC embedded in the ESP32 system-on-a-chip microcontroller.

\subsection{Test T.3. main results and proposed improvements}

This test procedure was used to characterise the performances of two different types of lithium batteries under the actual operative temperature in case of agriculture applications. The battery $\mathrm{A}$ is a LiNiCoMnO2 type (inr18650-35e), while the battery $\mathrm{B}$ is a LiFePo4 (HTCFR26650). The battery A is characterised by high specific energy and an operating voltage range between $3 \mathrm{~V}$ and $4 \mathrm{~V}$. Instead, the battery $\mathrm{B}$ guarantees a constant voltage output to supply the microcontroller, but it is characterised by a low-density charge. Moreover, according to the datasheet, the LiFePo4 batteries guarantee good performance in a larger temperature range.

During the thermal test an active load was used to discharge the batteries ensuring a constant discharge current of $300 \mathrm{~mA}$. This value was chosen since it is the average current consumption of the whole system during the data transmission phase. Figure 10 shows the experimental results achieved during the thermal cyclic test of the battery A (LiNiCoMnO2 type) using

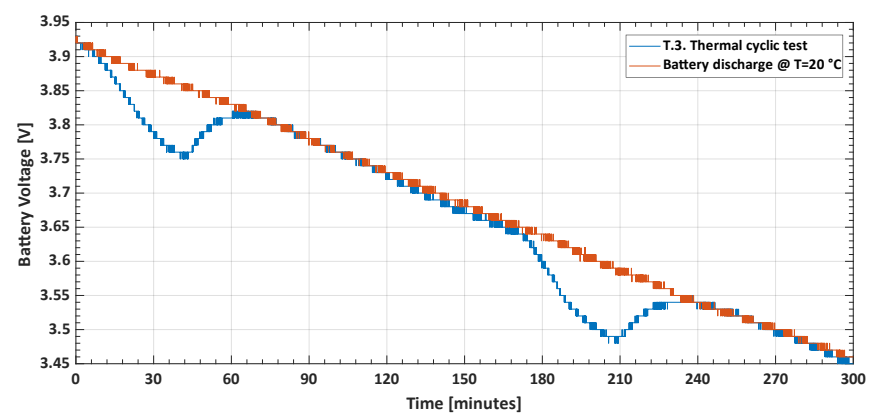

Figure 10. Battery discharge test for LiNiCoMnO2 battery: trend achieved at $20{ }^{\circ} \mathrm{C}$ constant temperature (red line) and trend achieved during thermal cyclic test T.3. (blue line).

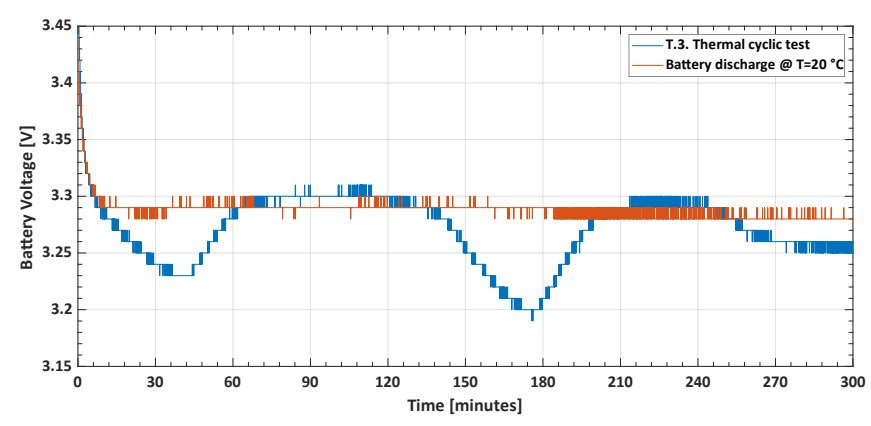

Figure 11. Battery discharge test for LiFePo4 battery: trend achieved at $20^{\circ} \mathrm{C}$ constant temperature (red line) and trend achieved during thermal cyclic test T.3. (blue line).

a blue line to represent the battery voltage during the discharge. The data were compared with a reference discharge voltage (red trend) measured maintaining a constant temperature of $20^{\circ} \mathrm{C}$. As expected, the reference discharge at room temperature exhibits a linear trend characterised by a negative slope (called $\Delta V$ in the following) strictly related to the constant discharge current forced by the active load.

Instead, the blue trend in Figure 10, achieved during the thermal cyclic test, highlights some deviation compared to the nominal trend during the cold phase of the cyclic test.

Specifically, the "V-shape trend" highlighted by the blue line in Figure 10 refers to temperature lower than $0{ }^{\circ} \mathrm{C}$. More in detail, when temperature is lowered under $0{ }^{\circ} \mathrm{C}$ the discharge rate of the battery suddenly increases, producing a remarkable decrease of the negative slope $\Delta V$. Then, when temperature starts to increase, the figure shows a counterintuitive behaviour: the battery voltage increases even though the battery is always on discharge phase. This increase of discharge rate at very low temperature could become remarkable in case of an exposition for a long period with really cold temperature. For this reason, the fixture of the solar panel that charges the batteries must be oriented with a proper slope in order to optimise the charge during winter.

Figure 11 shows the experimental results achieved during the thermal cyclic test of the battery $\mathrm{B}(\mathrm{LiFePo} 4$ type) using a blue line to represent the battery voltage during the discharge. Also in this case the data were compared with a reference discharge voltage (red trend) measured maintaining a constant temperature of $20{ }^{\circ} \mathrm{C}$. As expected, the LiFePo4 battery shows a constant voltage during the discharge phase. Despite this, during the thermal cyclic test also the LiFePo4 battery shows a "V-shape trend". For these reasons, considering the higher specific energy of the LiNiCoMnO2, the latter should be used in the sensor node.

\section{CONCLUSIONS}

The paper deals with the design optimisation of a sensor node, used in a wireless mesh network, under temperature stress. Since there is not a specific standard for this kind of system, a customised test plan was developed in this work based on three temperature-based stress tests. Moreover, an automatic measurement setup was designed and implemented to monitor the performances of the system during the test. The aim of the first temperature test (Test T.1.) was to observe the effects of high temperature on the hardware and firmware bugs, looking for any anomalies from the correct functioning. One of the main unexpected finding is an increase of the current consumption 
during the sleep phase when temperature overpass a certain threshold. In particular, a $4.5 \mathrm{~mA}$ step was verified above a specific temperature. This step is not due to a permanent failure, because during the cooling phase the current returns to its normal value at approximately the same temperature. This unexpected behaviour can lead to an increase of the power consumption of the sensor node and a solution must be considered.

The second temperature test (Test T.2.) aimed at verifying the performances of the Analog-to-Digital Converter (ADC) and Digital-to-Analog Converter (DAC) embedded in the microcontroller ESP32. The DACs does not highlight any particular problems, while the ADC embedded in the ESP32 shows three main drawbacks: a significant offset at room temperature, thermal instability and a remarkable data dispersion. For these reasons, it is recommended to use an external ADS1115 Analog-to-Digital converter which has provided better performances during the test.

Finally, test T.3. characterised the behaviour of two different types of batteries under thermal stress focusing on the discharge rate at cold temperature. The test highlights the importance of a proper solar panel orientation to optimise the batteries charge during winter.

\section{REFERENCES}

[1] G. D'Emilia, A. Gaspari, Data validation techniques for measurements systems operating in a Idustry 4.0 Scenario a condition monitoring application, in 2018 Workshop on Metrology for Industry 4.0 and IoT, Brescia, Italy, 16-18 April 2018, pp. 112-116.

DOI: $10.1109 /$ METROI4.2018.8428317

[2] M. Carratu, C. Liguori, A. Pietrosanto, M. O’Nils, J. Lundgren, A novel IVS procedure for handling Big Data with Artificial Neural Networks, in 2020 IEEE International Instrumentation and Measurement Technology Conference (I2MTC), Dubrovnik, Croatia, 25-28 May 2020, pp. 1-6. DOI: $10.1109 /$ I2MTC43012.2020.9128500

[3] E. Petritoli, F. Leccese, M. Botticelli, S. Pizzuti, F. Pieroni, A RAMS analysis for a precision scale-up configuration of "Smart Street" pilot site: an Industry 4.0 Case Study, ACTA IMEKO 8(2) (2019), pp. 3-11.

DOI: $10.21014 /$ acta imeko.v8i2.614

[4] G. D'Emilia, A. Gaspari, E. Natale, Mechatronics applications of measurements for smart manufacturing in an industry 4.0 scenario, IEEE Instrum. Meas. Mag. 22(2) (2019), pp. 35-43. DOI: $10.1109 /$ MIM.2019.8674633

[5] M. Carratu, M. Ferro, A. Pietrosanto, V. Paciello, Smart power meter for the IoT, in 2018 IEEE 16th International Conference on Industrial Informatics (INDIN), Porto, Portugal, 18-20 July 2018, pp. 514-519.

DOI: $10.1109 /$ INDIN.2018.8472018

[6] G. D’Emilia, A. Gaspari, E. Hohwieler, A. Laghmouchi, E. Uhlmann, Improvement of Defect Detectability in Machine Tools Using Sensor-based Condition Monitoring Applications, Procedia CIRP 67 (2018), pp. 325-331.

DOI: $10.1016 /$ i.procir.2017.12.221

[7] E. Petritoli, F. Leccese, G. S. Spagnolo, In-line quality control in semiconductors production and availability for Industry 4.0, in 2020 IEEE International Workshop on Metrology for Industry 4.0 \& IoT, Roma, Italy, 3-5 June 2020, pp. 665-668. DOI: $10.1109 /$ MetroInd4.0IoT48571.2020.9138296

[8] M. Carratu, A. Pietrosanto, P. Sommella, V. Paciello, A wearable low-cost device for measurement of human exposure to transmitted vibration on motorcycle, in 2019 II Workshop on Metrology for Industry 4.0 and IoT (MetroInd4.0\&IoT), Naples, Italy, 4-6 June 2019, pp. 329-333.

DOI: $10.1109 /$ METROI4.2019.8792855
[9] F. Lamonaca, C. Scuro, P. F. Sciammarella, R. S. Olivito, D. Grimaldi, D. L. Carnì, A layered IoT-based architecture for a distributed structural health monitoring system, ACTA IMEKO 8(2) (2019), pp. 45-52.

DOI: $10.21014 /$ acta imeko.v8i2.640

[10] M. Catelani, L. Ciani, V. Luongo, R. Singuaroli, Evaluation of the Safe Failure Fraction for an electromechanical complex system: remarks about the standard IEC61508, in 2010 IEEE Instrumentation \& Measurement Technology Conference Proceedings, Austin, TX, USA, 3-6 May 2010, pp. 949-953. DOI: 10.1109/IMTC.2010.5488034

[11] M. Catelani, L. Ciani, A. Bartolini, G. Guidi, G. Patrizi, Standby redundancy for reliability improvement of wireless sensor network, in 2019 IEEE 5th International forum on Research and Technology for Society and Industry (RTSI), Florence, Italy, 9-12 Sept. 2019, pp. 364-369. DOI: $10.1109 /$ RTSI.2019.8895533

[12] A. P. J. Lindsey, S. Murugan, R. E. Renitta, Microbial disease management in agriculture: Current status and future prospects, Biocatal. Agric. Biotechnol. 23 (2020)art. 101468. DOI: $\underline{10.1016 / \text { i.bcab.2019.101468 }}$

[13] H. Zia, N. R. Harris, G. V. Merrett, M. Rivers, N. Coles, The impact of agricultural activities on water quality: A case for collaborative catchment-scale management using integrated wireless sensor networks, Comput. Electron. Agric. 96 (2013), pp. 126-138. DOI: $10.1016 /$ i.compag.2013.05.001

[14] G. Vellidis, M. Tucker, C. Perry, C. Kvien, C. Bednarz, A real-time wireless smart sensor array for scheduling irrigation, Comput. Electron. Agric. 61(1) (2008), pp. 44-50. DOI: $10.1016 /$ i.compag.2007.05.009

[15] J. McCulloch, P. McCarthy, S. M. Guru, W. Peng, D. Hugo, A. Terhorst, Wireless sensor network deployment for water use efficiency in irrigation, in Proceedings of the workshop on Realworld wireless sensor networks - REALWSN '08, Glasgow Scotland, 1 April, 2008, pp. 46-50.

DOI: $\underline{10.1145 / 1435473.1435487}$

[16] M. Lezoche, J. E. Hernandez, M. del M. E. Alemany Díaz, H. Panetto, J. Kacprzyk, Agri-food 4.0: A survey of the supply chains and technologies for the future agriculture, Comput. Ind. 117 (2020) art. 103187. DOI: $10.1016 /$ i.compind.2020.103187

[17] F. Al-Turjman, The road towards plant phenotyping via WSNs: An overview, Comput. Electron. Agric. 161 (2019), pp. 4-13. DOI: $10.1016 /$ i.compag. 2018.09.018

[18] M. Younis, K. Akkaya, Strategies and techniques for node placement in wireless sensor networks: A survey, Ad Hoc Networks 6(4) (2008), pp. 621-655. DOI: $10.1016 /$ i.adhoc.2007.05.003

[19] F. M. Al-Turjman, A. E. Al-Fagih, W. M. Alsalih, H. S. Hassanein, Reciprocal public sensing for integrated RFID-sensor networks, in 2013 9th International Wireless Communications and Mobile Computing Conference (IWCMC), Sardinia, Italy, 1-5 July 2013, pp. 746-751. DOI: $10.1109 /$ IWCMC.2013.6583650

[20] F. M. Al Turjman, H. S. Hassanein, Towards augmented connectivity with delay constraints in WSN federation, Int. J. Ad Hoc Ubiquitous Comput. 11(2/3) (2012), pp. 97-108. DOI: 10.1504/IJAHUC.2012.050273

[21] Y. Wang, X. Li, W.-Z. Song, M. Huang, T. A. Dahlberg, Energyefficient localized routing in random multihop wireless networks, IEEE Trans. parallel Distrib. Syst. 22(8) (2011), pp. 1249-1257. DOI: $10.1109 /$ TPDS.2010.198

[22] A. M. Patel, M. M. Patel, A survey of energy efficient routing protocols for mobile ad- hoc networks, Int. J. Eng. Res. Technol. 1(10) (2012), pp. 1-6.

[23] R. Yan, H. Sun, Y. Qian, Energy-Aware Sensor node design with its application in wireless sensor networks, IEEE Trans. Instrum. Meas. 62(5) (2013), pp. 1183-1191. DOI: $\underline{10.1109 / T I M .2013 .2245181}$ 
[24] M. T. Penella, M. Gasulla, Runtime extension of low-power wireless sensor nodes using hybrid-storage units, IEEE Trans. Instrum. Meas. 59(4) (2010), pp. 857-865. DOI: $10.1109 /$ TIM.2009.2026603

[25] L. Gasparini, R. Manduchi, M. Gottardi, D. Petri, An ultralowpower wireless camera node: Development and performance analysis, IEEE Trans. Instrum. Meas. 60(12) (2011), pp. 3824 3832 .

DOI: $\underline{10.1109 / T I M .2011 .2147630}$

[26] M. Lazzaroni et al., Thermal modeling and characterization for designing reliable power converters for LHC power supplies, ACTA IMEKO 3(4) (2014), pp. 17-25.

DOI: $10.21014 /$ acta imeko.v3i4.147

[27] L. Cristaldi, M. Khalil, P. Soulatintork, A root cause analysis and a risk evaluation of PV balance of system failures, ACTA IMEKO 6(4) (2017), pp. 113-120. DOI: $10.21014 /$ acta imeko.v6i4.425

[28] L. Varandas, P. D. Gaspar, M. L. Aguiar, Standalone Docking station with combined charging methods for agricultural mobile robots, Int. J. Mech. Mechatronics Eng. 13(1) (2019), pp. 38-42. DOI: $10.5281 /$ zenodo.3607799

[29] H. Chen, W. Wang, B. Sun, J. Weng, F. Tie, Design of a WSN node for rice field based on hybrid antenna, in 2017 International Conference on Computer Network, Electronic and Automation (ICCNEA), Xi'an, China, 23-25 Sept. 2017, pp. 276-280. DOI: $10.1109 /$ ICCNEA.2017.101

[30] X. Jiaxing, G. Peng, W. Weixing, L. huazhong, X. Xin, H. Guosheng, Design of wireless sensor network bidirectional nodes for intelligent monitoring system of micro-irrigation in litch orchards, IFAC-PapersOnLine 51(17) (2018), pp. 449-454. DOI: $\underline{10.1016 / \text { i.ifacol.2018.08.176 }}$

[31] S. Tenzin, S. Siyang, T. Pobkrut, T. Kerdcharoen, Low cost weather station for climate-smart agriculture, in 2017 9th International Conference on Knowledge and Smart Technology (KST), Chonburi, Thailand, 1-4 Feb. 2017, pp. 172-177. DOI: $10.1109 /$ KST.2017.7886085

[32] L. Ciani, D. Galar, G. Patrizi, Improving context awareness reliability estimation for a wind turbine using an RBD model, in 2019 IEEE International Instrumentation and Measurement Technology Conference (I2MTC), Auckland, New Zealand, 20-23 May 2019, pp. 1-6. DOI: 10.1109/I2MTC.2019.8827041

[33] D. Capriglione et al., Development of a test plan and a testbed for performance analysis of MEMS-based IMUs under vibration conditions, Measurement 158 (2020), p. 107734.

DOI: $10.1016 /$ i.measurement.2020.107734

[34] D. Capriglione et al., Experimental analysis of IMU under vibration, in 16th IMEKO TC10 Conference 2019 - Testing, Diagnostics and Inspection as a Comprehensive Value Chain for Quality and Safety, Berlin, Germany, 3-4 Sept. 2019, pp. 26-31. Online [Accessed 09 June 2021]

https://www.imeko.org/publications/tc10-2019/IMEKOTC10-2019-002.pdf

[35] L. Ciani, G. Guidi, Application and analysis of methods for the evaluation of failure rate distribution parameters for avionics components, Measurement 139 (2019), pp. 258-269. DOI: $10.1016 / \mathrm{i}$. measurement.2019.02.082

[36] M. Catelani, L. Ciani, Experimental tests and reliability assessment of electronic ballast system, Microelectron. Reliab. 52(9-10) (2012), pp. 1833-1836.

DOI: $10.1016 /$ i.microrel.2012.06.077

[37] M. Carratu, M. Ferro, A. Pietrosanto, P. Sommella, V. Paciello, A smart wireless sensor network for PM10 Measurement, in 2019 IEEE International Symposium on Measurements \& Networking (M\&N), Catania, Italy, 8-10 July 2019, pp. 1-6. DOI: $10.1109 /$ IWMN.2019.8805015

[38] L. Ciani, A. Bartolini, G. Guidi, G. Patrizi, Condition monitoring of wind farm based on wireless mesh network, in 16th IMEKO TC10 Conference 2019 - Testing, Diagnostics and Inspection as a Comprehensive Value Chain for Quality and Safety, Berlin,
Germany, 3-4 Sept. 2019, pp. 39-44. Online [Accessed 09 June 2021] https://www.imeko.org/publications/tc10-2019/IMEKOTC10-2019-004.pdf

[39] M. Catelani, L. Ciani, A. Bartolini, G. Guidi, G. Patrizi, Characterization of a low-cost and low-power environmental monitoring system, in 2020 IEEE International Instrumentation and Measurement Technology Conference (I2MTC), Dubrovnik, Croatia, 25-28 May 2020. DOI: 10.1109/I2MTC43012.2020.9129274

[40] M. Cagnetti, F. Leccese, D. Trinca, A new remote and automated control system for the vineyard hail protection based on ZigBee sensors, raspberry-Pi electronic card and WiMAX, Journal Agric. Sci. Technol. 3 (2013), pp. 853-864.

[41] L. Ciani, A. Bartolini, G. Guidi, G. Patrizi, A hybrid tree sensor network for a condition monitoring system to optimise maintenance policy, ACTA IMEKO 9(1) (2020), pp. 3-9. DOI: $10.21014 /$ acta imeko.v9i1.732

[42] Y. Zhang, L. Jijun, H. Hu, Wireless Mesh Networking: Architectures, Protocols and Standards. Tailor \& Francis Group, New York, USA, 2007, ISBN: 9780429133107

[43] X. Zhu, Y. Lu, J. Han, L. Shi, Transmission reliability evaluation for wireless sensor networks, Int. J. Distrib. Sens. Networks 12(2) (2016), p. 1346079. DOI: $10.1155 \% 2 \mathrm{~F} 2016 \% 2 \mathrm{~F} 1346079$

[44] D. Capriglione et al., Characterization of inertial measurement units under environmental stress screening, in 2020 IEEE International Instrumentation and Measurement Technology Conference (I2MTC), Dubrovnik, Croatia, 25-28 May 2020, pp. $1-6$. DOI: $10.1109 /$ I2MTC43012.2020.9129263

[45] M. Catelani, L. Ciani, G. Guidi, M. Venzi, Parameter estimation methods for failure rate distributions, in 14th IMEKO TC10 Workshop on Technical Diagnostics 2016: New Perspectives in Measurements, Tools and Techniques for Systems Reliability, Maintainability and Safety, Milan, Italy, June 27-28, 2016, pp. 441445. Online [Accessed 09 June 2021] https://www.imeko.org/publications/tc10-2016/IMEKOTC10-2016-083.pdf

[46] MIL-STD-810G, "Environmental Engineering Considerations and Laboratory Tests," no. October. US Department of Defense, Washington DC, 2008.

[47] IEC 60068-2-14, "Environmental testing Part 2-14: tests - Test N: Change of temperature." International Electrotechnical Commission, 2011.

[48] IEC 60068-5-2, "Environmental testing - Part 5: Guide to drafting of test methods - Terms and definitions." International Electrotechnical Commission, 1990.

[49] IEC 60068-2-2, "Environmental testing - Part 2-2: Tests - Test B: Dry heat." International Electrotechnical Commission, 2007.

[50] IEC 60068-2-38, "Environmental testing Part 2: Tests - Test $\mathrm{Z} / \mathrm{AD}:$ Composite temperature/humidity cyclic test." International Electrotechnical Commission, 2009.

[51] JEDEC Solid State Technology, "JEDEC STANDARD: Temperature cycling." JESD22-A104E, 2014.

[52] IEST-RP-PR003.1, "HALT and HASS." Institute of Environmental Sciences and Technology - Product Reliability Division, 2012.

[53] A. Eddahech, O. Briat, J.-M. Vinassa, Performance comparison of four lithium-ion battery technologies under calendar aging, Energy 84 (2015), pp. 542-550. DOI: $10.1016 /$ i.energy. 2015.03.019

[54] T. Huria, M. Ceraolo, J. Gazzarri, R. Jackey, High fidelity electrical model with thermal dependence for characterization and simulation of high power Lithium battery cells, 2012 IEEE International Electric Vehicle Conference, 4-8 March 2012, Greenville, SC, USA. DOI: $10.1109 /$ IEVC. 2012.6183271

[55] N. Omar et al., Lithium iron phosphate based battery Assessment of the aging parameters and development of cycle life 
model, Appl. Energy 113 (2014), pp. 1575-1585.

DOI: $10.1016 /$ i.apenergy.2013.09.003

[56] E. Locorotondo, L. Pugi, L. Berzi, M. Pierini, G. Lutzemberger, Online Identification of Thevenin Equivalent Circuit Model Parameters and Estimation State of Charge of Lithium-Ion Batteries, in 2018 IEEE International Conference on Environment and Electrical Engineering and 2018 IEEE Industrial and Commercial Power Systems Europe (EEEIC / I\&CPS Europe), Palermo, Italy, 12-15 June 2018, pp. 1-6. DOI: 10.1109/EEEIC.2018.8493924
[57] L. Ciani, M. Catelani, A. Bartolini, G. Guidi, G. Patrizi, Electrical characterization of a monitoring system for precision farming under temperature stress, in 24th IMEKO TC4 International Symposium and 22nd International Workshop on ADC and DAC Modelling and Testing, Palermo, Italy, 14-16 Sept. 2020, pp. 270 275. Online [Accessed 14 June 2021]

https:/ /www.imeko.org/publications/tc4-2020/IMEKO-TC42020-51.pdf 